\title{
Internuclear ophthalmoplegia of abduction: clinical and electrophysiological data on the existence of an abduction paresis of prenuclear origin
}

\author{
Frank Thömke, Hanns Christian Hopf, Günter Krämer
}

\begin{abstract}
Three patients showed unilateral and five bilateral abduction paresis. Five had associated adduction nystagmus of the contralateral eye. Electrophysiological testing of masseter and blink reflexes indicated an ipsilateral rostral pontine or mesencephalic lesion, and excluded a lesion of the infranuclear portion of the abducens nerve. Abduction paresis was attributed to impaired inhibition of the tonic resting activity of the antagonistic medial rectus muscle. The prenuclear origin of the disorder is based on morphological and neurophysiological evidence of an ipsilateral inhibitory connection between the paramedian pontine reticular formation and the oculomotor nucleus running close to but separated from the medial longitudinal fasciculus.
\end{abstract}

In 1923 Lutz $^{1}$ proposed the existence of an abduction paresis of prenuclear origin ("ophthalmoplegia internuclearis posterior", pINO). As his basic neuroanatomical assumptions were erroneous, the existence of a pINO remained controversial. However, patients have been reported with abduction paresis, which differed from abducens nerve palsy in several aspects, such as, absence of strabismus and diplopia in the primary position, ${ }^{2-5}$ adduction nystagmus of the contralateral eye on lateral gaze, ${ }^{346}$ isolated impairment of saccadic abduction movements, ${ }^{7}$ and unimpaired abduction during caloric stimulation. ${ }^{8}$

There has been little agreement on the location of the responsible lesion and the pathophysiological explanation. Some authors, rejecting the existence of a prenuclear abduction paresis, attributed such cases to a pontine lesion involving the abducens nerve along its infranuclear intrapontine course. ${ }^{910}$ Others postulated decreased excitation of lateral rectus motor neurons due to a lesion of prenuclear structures, that is, aberrant "pyramidal tract" fibres to the abducens nucleus ${ }^{11}$ or the connection between the paramedian pontine reticular formation (PPRF) and the ipsilateral abducens nucleus. ${ }^{57}$ An impaired inhibition of the antagonistic medial rectus muscle was discussed by Collard et $a l^{4}$ suggesting a medial longitudinal fasciculus (MLF) lesion contralateral to the paretic eye. We re-examine this issue based on the findings in eight patients with electrophysiological evidence of a rostral pontine and/or mesencephalic lesion ipsilateral to the eye showing abduction paresis.

\section{Case reports}

\section{Patient 1}

A 63 year old woman with a five year history of atrial fibrillation and arterial hypertension suddenly developed diplopia and unsteadiness of gait. On admission she was somnolent and disoriented in time and place. Examination showed paralysis of upward and downward gaze and convergence. Abduction of the right orthophoric eye was limited to $30^{\circ}$. The gait was ataxic with a tendency to fall backwards. After three days she regained full orientation. Neuro-ophthalmological findings were unchanged and she complained of diplopia on gaze to the right. CT scan was normal. After three weeks abduction of the right eye was restored.

Patient 2

A 58 year old man who had experienced diabetes mellitus for 20 years, insulin dependent for six months, had sudden diplopia and mild dull headache. On examination abduction of the slightly esotropic $\left(2^{\circ}\right)$ right eye was limited to $20^{\circ}$ and there was additional adduction nystagmus on the left eye. Ankle jerks were diminished bilaterally. CSF showed slight pleocytosis $(9$ cells $/ \mu \mathrm{l})$ and increased protein content (126 mg/dl; IgG: $16 \cdot 2 \mathrm{mg} / \mathrm{dl})$. CT scan was normal. Complete clinical recovery occurred after three months.

Patient 3

A 48 year old heavy smoking (40-50 cigarettes per day) man had sudden diplopia. On examination abduction of the left orthophoric eye was restricted to $40^{\circ}$ and the left superior oblique muscle was paretic. CSF was normal. CT and MRI scans revealed pre-existing small ischaemic lesions of the right temporo-occipital region and the right parietal lobe. The brainstem was not involved. Duplex sonography showed several arteriosclerotic plaques of the proximal internal carotid arteries. Transcranial Doppler sonography of the cerebral and vertebrobasilar arteries was normal. After three weeks the clinical abnormalities had restored. Patient 4

A 65 year old man who had experienced type II diabetes for one year had diplopia when looking to the left and mild diffuse dull headache. On examination abduction of the slightly esotropic $\left(3^{\circ}\right)$ left eye was limited to $30^{\circ}$. Bilateral loss of ankle jerks and impaired vibration sense were 
attributed to diabetic neuropathy. Two days later he also noticed diplopia when looking to the right. Abduction of the orthophoric right eye was now limited to $20^{\circ}$ and after four days to $10^{\circ}$ on lateral gaze and during ocular cephalic reflex. There was additional adduction nystagmus on the left eye. CSF protein was slightly increased $(49 \mathrm{mg} / \mathrm{dl})$. CT and MRI scans were normal. There was complete clinical recovery after six months.

Patient 5

A 69 year old man who had had diabetes mellitus for 15 years, and was insulin dependent for one year, suddenly experienced diplopia and violent left fronto-temporal headache. Examination four days later showed restricted abduction (to $30^{\circ}$ ) of the left orthophoric eye and additional paresis of the left superior oblique muscle. Decreased ankle jerks, distal hypesthesia and impaired vibration sense were attributed to diabetic neuropathy. CSF protein was increased (154 mg/dl; IgG: $13.2 \mathrm{mg} / \mathrm{dl}$, no oligoclonal bands of IgG). CT was normal. After two weeks, abduction paresis of the left eye had improved to $40^{\circ}$.

Patient 6

A 75 year old woman who had experienced type II diabetes and arterial hypertension for four years developed violent headache with bifrontal accentuation during the night. The next morning she noticed diplopia and unsteadiness of gait. On examination abduction of the orthophoric right eye was limited to $20^{\circ}$ and there was adduction nystagmus on the left eye. Tandem walking was unsteady with a tendency to fall to the right. The ankle jerks were bilaterally decreased. CSF was normal. CT scan was normal including thin sections of the brainstem. After two weeks abduction paresis of the right eye had improved to $30^{\circ}$.

Patient 7

A 73 year old man with arterial hypertension for five years and type II diabetes for six months suddenly noted diplopia. Examination showed slight esotropia $\left(2^{\circ}\right)$ and limited abduction (to $20^{\circ}$ ) of the right eye on lateral gaze and during ocular cephalic reflex. There was adduction nystagmus of the left eye. Tandem walking was unsteady with a tendency to fall to the right. There was a predominantly sensory neuropathy with bilaterally decreased knee jerks, loss of ankle jerks, distal hypalgesia, and impaired vibration sense. CSF protein was slightly increased $(57.4 \mathrm{mg} / \mathrm{dl})$. The clinical condition had completely recovered after three months.

Patient 8

A 74 year old woman with type II diabetes for 20 years noticed sudden diplopia when looking to the right. On examination abduction of the right orthophoric eye was restricted to $20^{\circ}$. Bilaterally decreased ankle jerks and impaired vibration sense at the ankles were attributed to diabetic neuropathy. After two weeks abduction of the right eye had improved to $50^{\circ}$.

\section{Methods}

Horizontal eye movements were recorded separately for each eye. Surface electrodes were placed near the outer and inner canthi of the eyes and above and below the right eye for blink artifact detection. The bandwidth of the recording system was $0-40 \mathrm{~Hz}$. All signals were documented by a linear ink jet writer using paper speeds of 10 and $100 \mathrm{~mm} / \mathrm{s}$. Voluntary horizontal saccades were triggered by following a light spot projected on a screen $1.2 \mathrm{~m}$ in front of the patient. Target jumps of 20,30 and $40^{\circ}$ to the left or right from the primary position were used at random intervals. Peak velocities of six saccades of $30^{\circ}$ to either side were evaluated. The normal range of $30^{\circ}$ abduction saccades in 40 controls was 320 to $640 \%$ s. Interocular differences did not exceed $35^{\circ} / \mathrm{s}$.

The masseter reflex (MassR) was elicited by a brisk tap on the patient's jaw using a reflex hammer. The recording was triggered at the moment of the mechanical tap by a signal from a piezo-electric element mounted in the hammer. The MassR was recorded using surface electrodes with the recording electrode placed over the belly of the masseter muscle $(25 \mathrm{~mm}$ above the margin of the mandible) and the reference over the jugular bone at the lateral edge of the orbit. Ten successive events were averaged. The responses were considered abnormal using one or more of the following criteria: 1) Unilateral or bilateral loss with recovery at re-examination; 2) Unilateral or bilateral delay above the age related mean + $2.5 \mathrm{SD}$; 3) Right to left difference of $0.5 \mathrm{~ms}$ or more. In 30 controls older than $\mathbf{4 0}$ years the normal value was $7.6 \mathrm{~ms}$ and $2.5 \mathrm{SD}$ was 1.3 ms. The mean right to left difference was $0 \cdot 15$ ms and $2.5 \mathrm{SD}$ was $0.3 \mathrm{~ms}$. The criteria for MassR improvement at re-examination were a reappearance of the completely or partially $(>4$ in 10 trials) abolished responses and shortening of latency by $\geqslant 0.8 \mathrm{~ms}$.

The blink reflex (BR) was elicited by stimulating the supraorbital nerve on either side using rectangular stimuli of $0.1 \mathrm{~ms}$ duration, constant current of $25 \mathrm{~mA}$ and intervals of $10 \mathrm{~s}$. Responses from the orbicularis oculi muscles were recorded by surface electrodes with the recording electrode placed inferior to the lower lid halfway between the inner and outer edge of the orbit. Five consecutive events were evaluated. The ipsilateral and contralateral $R_{2}$ components were within normal limits in all our patients. The criteria of an abnormal $R_{1}$ response were: 1) Unilateral loss of $R_{1} ; 2$ ) Unilateral or bilateral delay above the age related mean $+2.5 \mathrm{SD} ; 3$ ) Right to left difference of $1.3 \mathrm{~ms}$ or more. In 30 controls older than 40 years the normal value was 10.7 ms and $2.5 \mathrm{SD}$ was $0.8 \mathrm{~ms}$. The mean right to left difference was $0.5 \mathrm{~ms}$ and $2.5 \mathrm{SD}$ was 0.7 $m s$. The criterion for $B R-R_{1}$ improvement was shortening of the latency by $\geqslant 1 \cdot 3 \mathrm{~ms}$.

For brainstem auditory evoked potentials (BAEP) rarefaction and condensation clicks of $70 \mathrm{~dB}$ above click hearing threshold with a repetition rate of $10 / \mathrm{s}$ were delivered monaurally. Responses were recorded by surface electrodes with the recording electrode placed over the mastoid and the reference over the vertex. Latencies were determined from 1000 averaged responses.

\section{Results}

The eight patients in this series showed abduction paresis with residual movements of 10 
Figure 1 Electrooculogram of patient 2 showing adduction paresis with hypermetric

abduction saccades and adduction nystagmus on the left eye. Saccades were performed from the primary position to the right at target jumps of $20^{\circ}$ $(A)$ and $40^{\circ}(B)$. (r right eye; l:left eye).

Figure 2 Electrooculogram of patient 4 showing asymmetrical bilateral abduction paresis with bilateral adduction nystagmus. Saccades were performed from the primary position to the right $(A)$ and left $(B)$ at target jumps of $30^{\circ}$. (r:right eye; l:left eye).
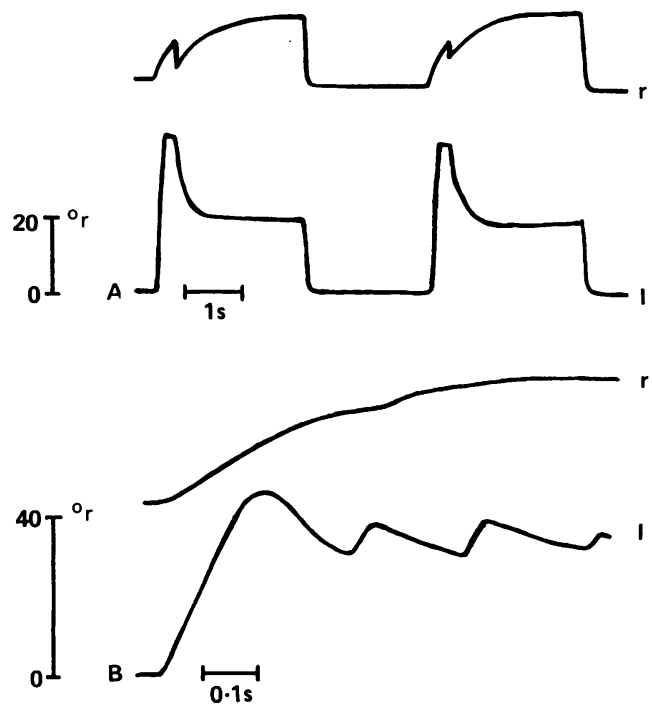

$40^{\circ}$. Clinically, the disorder was bilateral, though asymmetrical, in one (patient 4) and unilateral in the remaining seven. The paretic eye was orthophoric in patients $1,3,4$ (right eye), 5, 6, and 8 and slightly esotropic $\left(2-3^{\circ}\right)$ in patients 2, 4 (left eye), and 7. Adduction nystagmus on the contralateral eye was clinically observed in patients 2,4 (left eye), 6 and 7.

Electro-oculography (EOG) confirmed the clinical findings (fig 1) and additionally revealed adduction nystagmus on the eye contralateral to the lateral rectus paresis in patient 4 (right eye), fig 2 . In four of the seven patients with clinically unilateral abduction paresis EOG demonstrated additional slowing of abduction saccades of the contralateral eye (patients 5, 6, 7, 8) (fig 3, 4). Velocities were between 290 and $380 \%$ with interocular differences of 140 to $170^{\circ} / \mathrm{s}$ compared with adduction saccades of the opposite eye. This was associated with adduction nystagmus in three patients ${ }^{5-7}$ (fig 3,4). Thus adduction nystagmus on the contralateral eye was seen in one (patient 2) of three patients with strictly unilateral abduction paresis. Bilateral asymmetrical abduction paresis was associated with bilateral adduction nystagmus in three (patients 4,6,7) and with unilateral adduction

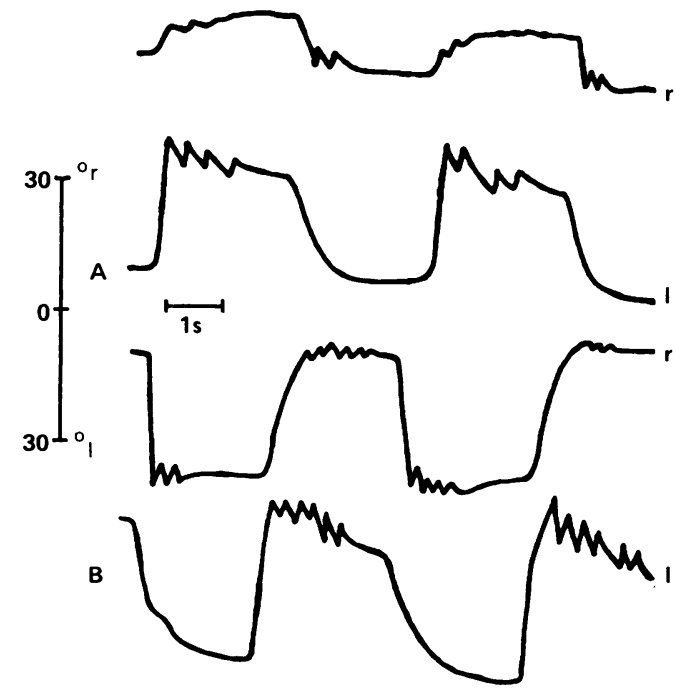

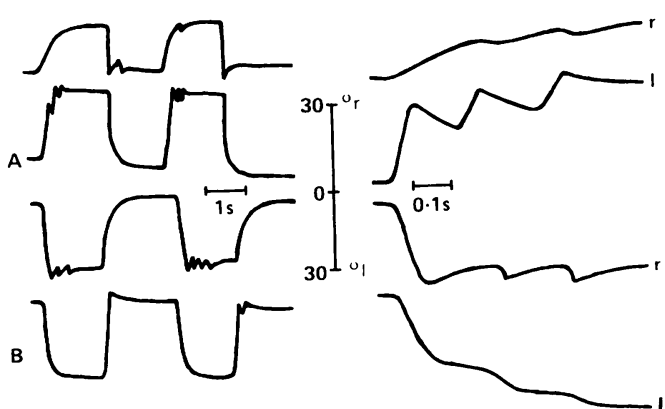

Figure 3 Electro-oculogram of patient 7 showing asymmetrical bilateral abduction paresis with bilateral adduction nystagmus. Saccades were performed from the primary position to the right $(A)$ and left $(B)$ at target jumps of $30^{\circ}$. (r:right eye; l:left eye).

nystagmus in one (patient 5). No nystagmus was seen in one (patient 8 ).

Patient 1 with unilateral abduction paresis had an additional paralysis of upward and downward gaze and of convergence. Additional unilateral superior oblique paresis was observed in patient 3 with unilateral abduction paresis on the paretic eye and in patient 5 with asymmetrical bilateral abduction paresis on the more severely affected eye.

MassR abnormalities were observed in all patients in this series (table). Those with unilateral abduction paresis (patients $1,2,3$ ) had unilateral MassR abnormalities ipsilateral to the paretic eye. Four of five patients $(5,6,7$, 8) with asymmetrical bilateral abduction paresis showed bilateral MassR changes. They were more pronounced ipsilateral to the more severely affected eye in patient 6 , and in patient 8 , the initially bilateral MassR abnormality changed into a unilateral one, which was ipsilateral to the more severely affected eye at re-examination. The MassR was unilaterally abnormal ipsilateral to the more severely affected eye in patient 4.

The BR- $R_{1}$ was unilaterally abnormal in 4 patients $(1,3,4,8)$ (table). Changes were ipsilateral to the paretic eye in patient 1 and 3 with unilateral abduction paresis and ipsilateral to the more severely affected eye in patient 4 and 8 with asymmetrical bilateral abduction paresis. BAEP waves $I$ to $V$ were normal in all patients.

Abduction paresis recovered (patients 1,2,3,

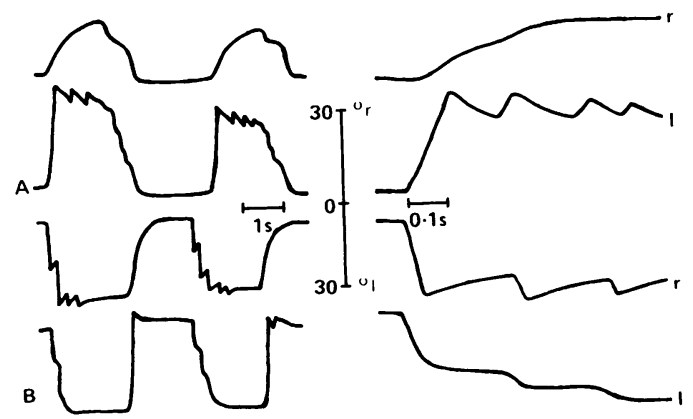

Figure 4 Electro-oculogram of patient 6 showing asymmetrical bilateral abduction paresis with bilateral adduction nystagmus. Saccades were performed from the primary position to the right $(A)$ and left $(B)$ at target jumps of $30^{\circ}$. (r:right eye; l:left eye). 
Table Alterations of the masseter reflex and the $R$, component of the blink reflex in three patients $(1,2,3)$ with unilateral and five $(4,5,6,7,8)$ with asymmetrical bilateral abduction paresis.

\begin{tabular}{|c|c|c|c|c|}
\hline \multirow[b]{2}{*}{ Patient } & \multicolumn{2}{|c|}{$\begin{array}{l}\text { Masseter reflex } \\
\text { Latency (ms) }\end{array}$} & \multicolumn{2}{|c|}{$\begin{array}{l}\text { Blink reflex } \mathbf{R}_{\mathbf{1}} \\
\text { Latency }(m s)\end{array}$} \\
\hline & Right & $L e f t$ & Right & Left \\
\hline $\begin{array}{l}\mathbf{1} \\
\text { after } 3 \text { weeks } \\
\mathbf{2} \\
\text { after } 3 \text { months } \\
\mathbf{3} \\
\text { after } 2 \text { weeks } \\
\mathbf{4} \\
\text { after } 6 \text { months } \\
5 \\
\text { after } 2 \text { weeks } \\
\mathbf{6} \\
\text { after } 2 \text { weeks } \\
7 \\
\text { after } 3 \text { months } \\
\mathbf{8} \\
\text { after } 2 \text { weeks }\end{array}$ & $\begin{array}{l}8 \cdot 9^{\star}(7) \\
8 \cdot 0(8) \\
8 \cdot 9 \star(7) \\
8 \cdot 0(9) \\
7 \cdot 9(10) \\
8 \cdot 1(10) \\
Z^{\star}(0) \\
8 \cdot 3(10) \\
12 \cdot 4(5) \\
9 \cdot 4(7) \\
Z^{\star}(1) \\
8 \cdot 1(6) \\
9 \cdot 3(8) \\
8 \cdot 5(10) \\
-{ }^{\star}(0) \\
C^{\star}(0)\end{array}$ & $\begin{array}{l}8 \cdot 2(10) \\
8 \cdot 2(10) \\
8 \cdot 2(8) \\
7 \cdot 9(10) \\
9 \cdot 3 \star(7) \\
8 \cdot 5(10) \\
8 \cdot 6(8) \\
8 \cdot 6(10) \\
10 \cdot 2(7) \\
9 \cdot 2(9) \\
8 \cdot 0(4) \\
7 \cdot 9(9) \\
9 \cdot 6(7) \\
8 \cdot 5(10) \\
-(0) \\
7 \cdot 3(9)\end{array}$ & $\begin{array}{l}11.0 \\
11 \cdot 1 \\
12 \cdot 7^{\star} \\
11.2 \\
11.5 \\
10.2\end{array}$ & $\begin{array}{l}12 \cdot 5^{\star} \\
11 \cdot 8^{\star} \\
10 \cdot 3 \\
10 \cdot 6 \\
11.0\end{array}$ \\
\hline
\end{tabular}

(Abnormal responses are given in bold print; ${ }^{\text {indicates }}$ abnormalities ipsilateral to the paretic eye in unilateral and ipsilateral to the more severely affected eye in asymmetrical bilateral abduction paresis; for masseter reflex, the numbers of responses obtained out of 10 trials are given in brackets)

4, and on the less severely affected eye in patients $5,6,7,8$ ) or improved (on the more severely affected eye in patients $5,6,7,8$ ) with recovery (patients $1,2,4,6,7$ ) or improvement (patients $3,5,7$ ) of MassR and $B R-R_{1}$ findings.

\section{Discussion}

In all patients peripheral causes of MassR impairment were excluded clinically by absence of masseter muscle paresis, sensory disturbance of the branches of the 5 th nerve and corneal reflex impairment. Under such conditions, a MassR abnormality has to be attributed to an ipsilateral upper pontine or mesencephalic lesion. ${ }^{1213}$ Associated MassR and $B R-R_{1}$ abnormalities indicate an ipsilateral rostral pontine lesion. ${ }^{14} 15$ Suprasegmental lesions have not been reported so far to influence the MassR and BR- $R_{1}$. Thus the findings in our patients are in favour of a rostral pontine and/or mesencephalic lesion ipsilateral to the abduction paresis. Improvement or normalisation of abduction paresis was always associated with improvement or normalisation of the electrophysiological findings. This strongly indicates that clinical, EOG and electrophysiological changes were caused by the same lesion. A lesion of the sixth cranial nerve as the cause of abduction paresis in our patients was very unlikely as there was no electrophysiological evidence for a midpontine or lower pontine lesion at the level of the infranuclear intrapontine course of the sixth nerve (normal ipsilateral and contralateral $\mathbf{R}_{2}$ components of the BR, normal BAEP waves I to III in all patients).

Electrophysiological testing suggests that the lesion is located ipsilateral to the abduction paresis at the upper pons or midbrain level. This location was evident in patient 1 from paralysis of upward and downward gaze and convergence ${ }^{1617}$ and is confirmed by previous observations. In a five year old girl with bilateral slowing of abduction saccades and bilateral adduction nystagmus ${ }^{7}$ and a 66 year old woman with bilateral abduction paresis, ${ }^{3}$ upgaze paresis and combined upgaze and convergence pareses, respectively, strongly indicated a rostral midbrain lesion. ${ }^{16}{ }^{17}$ Bilateral abduction paresis with upgaze palsy was observed in midbrain haemorrhage ${ }^{18}$ and unilateral abduction paresis with upgaze paralysis in ipsilateral meso-diencephalic haemorrhage. ${ }^{19}$ The midbrain location was obvious in two patients who developed a transient ipsilateral abduction paresis after unilateral mesencephalotomy. ${ }^{20}$

We suggest that the most probable cause of abduction paresis in our patients is impaired inhibition of the tonic resting activity of the ipsilateral medial rectus muscle. Impaired inhibition of the tonic resting activity of antagonistic eye muscles results in horizontal and vertical eye movement pareses despite normal activation of the agonists. ${ }^{21-23}$ The proposed location and pathophysiological explanation is also supported by the observation of unilateral abduction paresis with normal lateral rectus excitation but grossly impaired medial rectus inhibition in a patient with clinical evidence of an ipsilateral mesencephalic lesion (indicated by ipsilateral convergence paresis). ${ }^{21}$

Inhibition of medial rectus motor neurons has been attributed to an inhibitory action of MLF fibres. ${ }^{24}$ However, during saccades and pursuit eye movements MLF fibre activity is only associated with contraversive eye movements ${ }^{24} 25$ and no MLF activity was recorded ipsilateral to the abducting eye. ${ }^{24} 25$ Pola and Robinson ${ }^{24}$ proposed that inhibitory MLF fibres cross at the oculomotor nucleus level to contralateral medial rectus motor neurons. The absence of demonstrated crossing fibres ${ }^{26}{ }^{27}$ and the observation of impaired medial rectus inhibition on the eye ipsilateral to unilateral MLF lesions ${ }^{28-30}$ strongly contradicts this hypothesis.

Disynaptic inhibition of abducens nucleus motor neurons and internuclear neurons after unilateral stimulation of the contralateral PPRF $^{31}$ mediated by inhibitory burst neurons of the dorsomedial reticular formation, (which receive afferents from the ipsilateral PPRF and project to contralateral abducens nucleus, ${ }^{32}{ }^{33}$ ) was thought to involve the tonic resting activity of antagonistic eye muscles during lateral gaze. ${ }^{34}$ Inhibition of the lateral rectus muscle was attributed to inhibition of lateral rectus motor neurons and medial rectus inhibition was explained by inhibition of abducens nucleus internuclear neurons causing inhibition of the excitatory projections of these neurons via the MLF to contralateral medial rectus motor neurons ("disfacilitation"). ${ }^{34}$ However, 1) Loss of excitatory MLF fibre activity to medial rectus motor neurons was never followed by reduction of the tonic resting activity of the medial rectus muscle; $;^{28-30} 2$ ) Unilateral stimulation of inhibitory burst neurons caused abduction of the ipsilateral eye only when the eye was adducted (superimposed on continuous excitation of medial rectus motor neurons via the MLF), but not in the primary position (when there is no MLF fibre 
Figure 5 Hypothesis for a horizontal gaze inhibitory system (The pattern of excitation and inhibition is shown for leftward gaze. Black arrows: excitation; white arrows: inhibition; $L E$ : left eye; $R E$ : right eye; $L R$ : lateral rectus; $M R$. medial rectus; NVI: abducens nerve; $V I$. abducens nucleus; $N$ III : oculomotor nerve; III oculomotor nucleus; PPRF: paramedian pontine reticular formation; $M L F$ : medial longitudinal fasciculus, $P M L F$ : para-MLF $I B N$ : inhibitory burst neurons)

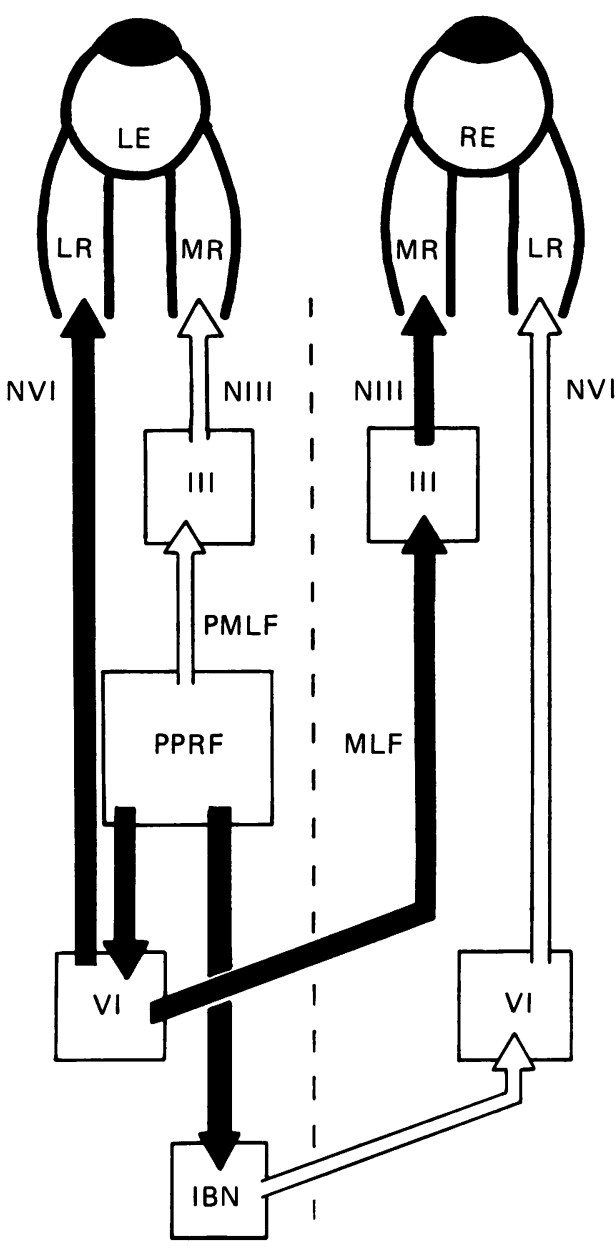

activity); ${ }^{35}$ 3) Bilateral interruption of the MLF and the inhibitory projections to the abducens nuclei causes bilateral INO and bilateral loss of lateral rectus inhibition but only mild impairment of medial rectus inhibition. ${ }^{22}$ These findings contradict the assumption that the MLF is a neural pathway for medial rectus inhibition.

In particular, the largely spared medial rectus inhibition after MLF destruction ${ }^{22}$ points to the existence of a separate inhibitory connection which was identified in experimental studies. ${ }^{3637}$ After bilateral MLF destruction, unilateral stimulation of inhibitory neurons of the PPRF between the fourth and sixth cranial nerve nuclei evoked monosynaptic inhibitory potentials in ipsilateral oculomotor nucleus neurons $\mathrm{s}^{36}$ and ipsilateral medial rectus motor neurons. ${ }^{37}$ Fibre degeneration studies in rabbits $^{38}$ and primates ${ }^{39}$ and autoradiographic studies in cats $^{33}$ and primates ${ }^{2640}$ showed an uncrossed connection between the PPRF and the oculomotor nucleus ascending adjacent to but separate from the $M L F^{2639}$ and approaching medial rectus motor neurons. ${ }^{40}$ Such fibres originate from the same neurons within the ipsilateral PPRF which generate inhibitory monosynaptic potentials to ipsilateral medial rectus motor neurons. ${ }^{41}$ This connection, which may be called the para-MLF, most likely mediates medial rectus inhibition. On the basis of these data we propose a modified concept of the prenuclear organisation of horizontal eye movements (fig 5). Accordingly, abduction paresis is due to impaired inhibition of medial rectus tonic resting activity following interruption of the para-MLF.

A small ischaemic lesion seems most likely in all our patients. Patients 2, 4, 5, 6, 7, 8 suffered from diabetes and patients 6 and 7 also had arterial hypertension; patient 1 had arterial hypertension and atrial fibrillation and patient 3 was a heavy smoker. The region in question is supplied by: a) A few long arteries originating from the basilar artery supplying the MLF and terminating in the para-MLF region; b) A few small branches of the medial cerebellar artery supplying the mesencephalic nucleus of the trigeminal nerve which also terminate in the para-MLF region; c) Small branches of the collicular artery approaching the paraMLF. ${ }^{4243}$

Obviously the territory of the para-MLF (fig 6) forms a watershed zone. Circulatory arrest of one of the long penetrating arteries of the basilar artery, which often show an asymmetric termination, ${ }^{43}$ may contribute to asymmetrical abduction paresis observed in five patients (4, $5,6,7,8)$. Also, a combined lateral rectus and superior oblique muscle paresis (patient 3,5 ) may occur from a single ischaemic midbrain lesion, since the para-MLF, the trochlear nerve after its crossing, and the mesencephalic nucleus of the trigeminal nerve are closely related at that site (44) (fig 6).

A brainstem lesion was not shown by CT (patients 1, 2, 3, 4, 5, 6) or MRI (patients 3, 4). However, such lesions are frequently too small to be detected, which recently has been illustrated in 11 patients with isolated diabetic oculomotor palsy due to midbrain lesions. ${ }^{13}$ Thinner slices $(3 \mathrm{~mm}$ instead of $10 \mathrm{~mm}$ in our patients) and Gadolinium-DTPA (not used in our patients) may improve the sensitivity of MRI in this condition.

In conclusion, we propose the existence of an abduction paresis of prenuclear origin on the basis of clinical and electrophysiological findings indicating a rostral pontine or mesencephalic lesion in eight patients. Abduction paresis is due to impaired inhibition of the tonic resting activity of the ipsilateral medial rectus muscle during lateral gaze. Such inhibition is triggered by the monosynaptic inhibitory potentials observed in medial rectus motor neurons after unilateral stimulation of PPRF neurons. The inhibitory potentials are mediated by an uncrossed connection between the PPRF and the oculomotor nucleus. This connection ascending in close proximity to the MLF may be called the para-MLF. Since the para-MLF is an internuclear connection the movement disorder resulting from its damage is appropriately termed internuclear ophthalmoplegia of abduction (INO-abd). The diagnosis of INO-abd should be considered in patients with an incomplete abduction paresis and clinical, morphological and/or electrophysiological evidence of an ipsilateral rostral pontine or mesencephalic lesion.

Orthophoria in the primary position as observed in patients 1, 3, 4 (right eye), 5, 6 and 8 is expected in INO-abd but occurs also in incomplete abducens nerve palsy. ${ }^{45}$ Mild 
Figure 6 Transverse section through the pontomesencephalic brainstem. (According to (44), course of the para-MLF according to $(26,39)$. The levels of the section are shown by the key diagram on the left.

(1) Main sensory nucleus of the trigeminal nerve;

(2) Mesencephalic nucleus of the trigeminal nerve (3) Motor nucleus of the trigeminal nerve; (4) PPRF Nucleus reticularis pontis caudalis; (5) Medial longitudinal fasciculus; (6) Genu of the facial nerve; (7) Mesencephalic tract of the trigeminal nerve; (8) Motor part of the trigeminal nerve; (9) Sensory part of the trigeminal nerve: (10) PPRF Nucleus reticularis pontis oralis; (11) Decussation of the trochlear nerves; (12)

Trochlear nerve; (13)

"Para" medial

longitudinal fasciculus; (14) trochlear nucleus;

(15) oculomotor nucleus;

(16) oculomotor nerve.

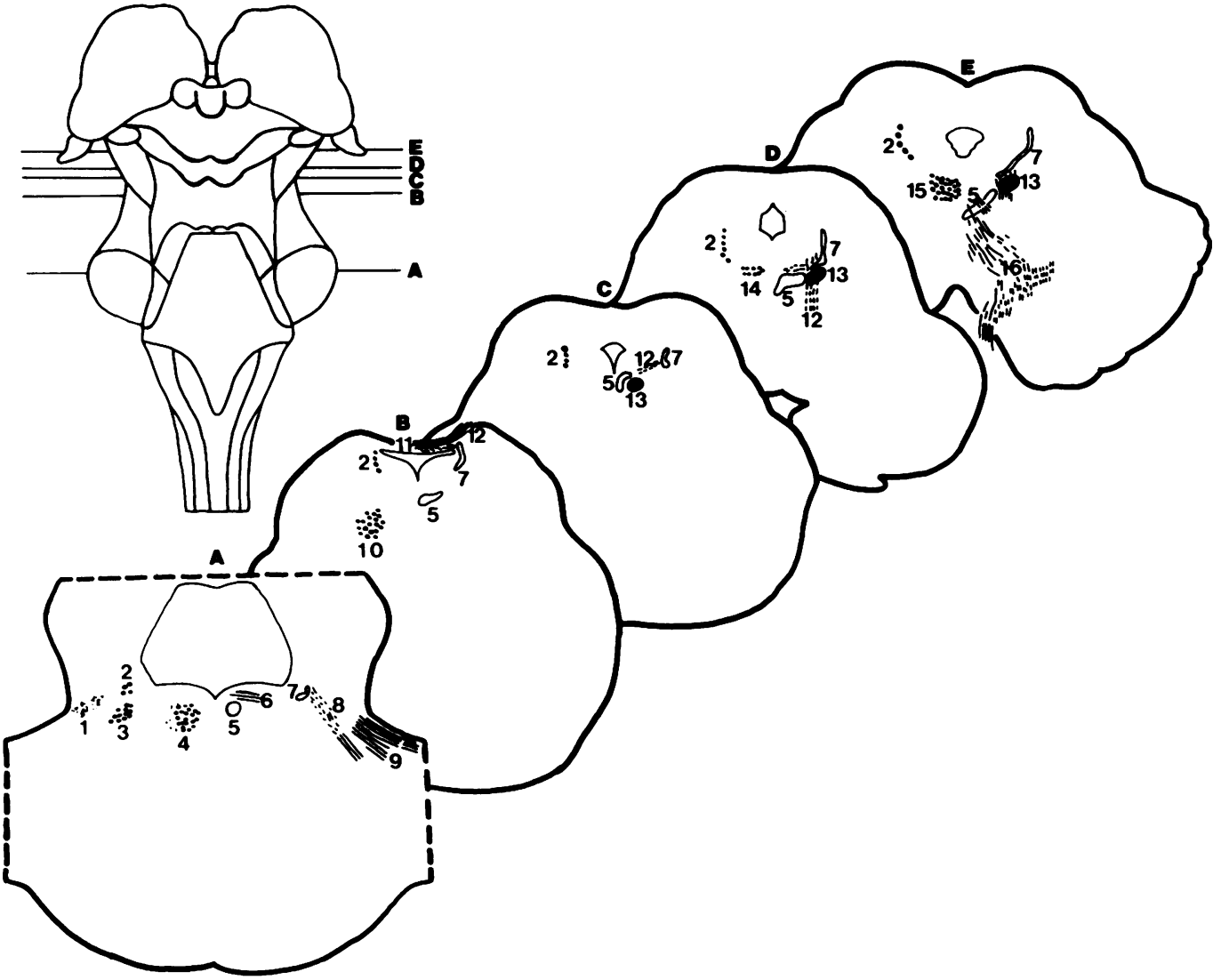

esotropia observed in patients 2,4 (left eye) and 7 does not exclude an INO-abd. In INO of adduction due to impaired prenuclear excitatory input to medial rectus motor neurons, exotropia of the paretic eye may occur. ${ }^{46}$ By analogy, mild esotropia in INO-abd is interpreted in terms of an impaired prenuclear inhibitory input to medial rectus motor neurons. Alternatively, dysfunction of vergence neurons may cause esotropia in midbrain lesions. ${ }^{47}$ Adduction nystagmus on the contralateral was seen in five of our patients. It is not a conclusive sign in individual patients indicating INO-abd as it may also occur in abducens nerve palsy. ${ }^{48}$ Diagnostic problems may arise in pseudo-abducens palsy with abduction paresis due to abnormal convergence impulses on lateral gaze described in midbrain tegmental lesions. ${ }^{49}$ But these patients show miosis on lateral gaze, ${ }^{49}$ which is not a feature of INO-abd.

1 Lutz A. Uber die Bahnen der Blickwendung und deren Dissoziierung. (Nebst eines Falles von Ophthalmoplegia internuclearis anterior in verbindung mit Dissoziierung der Bogengänge). Klin Monatsbl Augenheilkd 1923; 70:213-35.

2 Larmande A-M. La paralysie supranucléaire du VI. (dite ophthalmoplégie internucléaire postérieure). Arch $d$ Ophtalmol (Paris) 1969;29:521-30.

3 Schiffter R. Die internukleären Ophthalmoplegien. Klinische Analyse von 25 Krankheitsfallen. Nervenarz 1975;46:116-27.

4 Collard M, Eber AM, Streicher D, Rohmer F. L'ophthalmoplégie internucléaire postérieure-existe-t-elle? A propos de onze observations avec oculographie. Rev Neurol 1979;135:293-312.

5 Topilow HW. Posterior internuclear ophthalmoplegia of Lutz. Ann Ophthalmol 1981;13:221-6.

6 Bogousslavsky J, Regli F, Ostinelli B, Rabinowicz T. Paresis of lateral gaze alternating with so-called posterior internu- clear ophthalmoplegia. A partial pontine reticular formation-abducens nucleus syndrome. $J$ Neurol 1985;232: 38-42.

7 Kommerell G. Internuclear ophthalmoplegia of abduction. Isolated impairment of phasic ocular motor activity in supranuclear lesions. Arch Ophthalmol 1975;93:531-4.

8 Walsh FB, Hoyt WF Clinical Neuro-Ophthalmology, 3rd ed, Vol 1. Baltimore: Williams and Wilkins, 1969:239-43.

9 Fine M, MacGlashan CB. Unilateral internuclear ophthalmoplegia of vascular origin. Arch Ophthalmol 1956; 56:327-37.

10 Henn V, Büttner U, Büttner-Ennever JA Supranukleäre Organisation der Okulomotorik-physiologische und anatomische Grundlagen. In: Kommerell G, ed. Augenanatomische Grundlagen. In: Kommerell G, ed. AugenMünchen: Beromann 1978:129-41.

11 Rothstein TL, Alvord EC. Posterior internuclear ophthalmoplegia. A clinicopathological study. Arch Neurol 1971;24:191-202.

12 Ongerboer de Visser BW. Afferent limb of the human jaw reflex: electrophysiologic and anatomic study. Neurology 1982;32:563-6.

13 Hopf HC, Gutmann L. Diabetic 3rd nerve palsy: Evidence for a mesencephalic lesion. Neurology 1990;40:1041-5.

14 Kimura J. Clinical use of the electrically elicted blink reflex. In: Desmedt JE, ed. Motor control mechanisms in health and disease. New York: Raven Press 1983:773-86.

15 Hopf HC, Thömke F, Gutmann L. Mid brain versus pontine medial longitudinal fasciculus lesions. The utilization of masseter and blink reflexes. Muscle Nerve utilization of mass

16 Büttner-Ennever JA, Cohen B, Baumgartner G. Vertical gaze paralysis and the rostral interstitial nucleus of the medial longitudinal fasciculus. Brain 1982;105:125-49.

17 Pierrot-Deseilligny C, Chain F, Gray F, Serdaru M, Escourelle R, Lhermitte F. Parinaud's syndrome: electrooculographic and anatomic analysis of six vascular cases with deductions about vertical gaze organisation in the premotor structures. Brain 1982;105:667-96.

18 Weisberg LA. Mesencephalic hemorrhages: clinical and 36:713-6.

19 Körney S. Blickstörungen bei vasculären Herden des mesodiencephalen Ubergangsgebietes. Arch Psychiat $Z$ ges Neurol 1959;198:535-43.

20 Nashold BS, Gills JP. Ocular signs from brain stimulation and lesions. Arch Opthalmol 1967;77:609-18.

21 Orlowski WJ, Slomski P, Wojtowicz S. Bielschowsky-LutzCogan syndrome. Am J Ophthalmol 1965;59:416-30.

22 Burde RM, Lehman RAW, Roper-Hall G, Brooks J, Keltner JL. Experimental internuclear ophthalmoplegia. Brit ner JL. Experimental internucle

23 Pinhas I, Pinhas A, Goldhammer Y, Braham J. Progressive supranuclear palsy: Electromyographic examinations of eye muscles. Acta Neurol Scandinav 1978;58:304-8. computed tomographic correlations. Neurology 1986; 
24 Pola J, Robinson DA. An explanation of eye movements seen in internuclear ophthalmoplegia. Arch Neurol 1976 33:447-52.

25 King WM, Lisberger SG, Fuchs AF. Responses of fibers in the medial longitudinal fasciculus (MLF) of alert monkeys during horizontal and vertical conjugate eye movements evoked by vestibular or visual stimuli. J Neurophysiol 1976;39:1135-49.

26 Büttner-Ennever JA, Henn V. An autoradiographic study of the pathways from the pontine reticular formation of the pathways from the pontine reticular formation
involved in horizontal eye movements. Brain Res 1976; involved in

27 Steiger HJ, Büttner-Ennever JA. Oculomotor nucleus afferents in the monkey demonstrated with horseradish peroxidase. Brain Res 1979;160:1-15.

28 Loeffler JD, Hoyt WF, Slatt B. Motor excitation and inhibition in internuclear palsy. Arch Neurol 1966;15: 664-71.

29 Gonzalez C, Reuben RN. Ocular electromyography in the syndrome of the median longitudinal fasciculus. Patterns of inhibition and excitation. Am J Ophthalmol 1967;64:916-26.

30 Pierrot-Deseilligny C, Rigolet $\mathrm{MH}$, Chain F. Etude électromyographique de deux cas d'ophtalmoplégie internucléaire: Déductions physiopathologiques. Rev Neurol cleaire: Deductions physiop

31 Highstein SM, Maekawa K, Steinacker A, Cohen B. Synaptic input from the pontine reticular nuclei to abducens
motoneurons and internuclear neurons in the cat. Brain motoneurons and in

32 Scudder CA, Fuchs AF, Langer TP. Characteristics and functional identification of saccadic inhibitory burst neurons in the alert monkey. $J$ Neurophysiol 1988; 59:1430-54.

33 Graybiel AM. Direct and indirect preoculomotor pathways of the brainstem: An autoradiographic study of the pontine reticular formation in the cat. $J$ Comp Neurol 1977;175:37-78

34 Pierrot-Deseilligny C. Circuits oculomoteurs centraux. Rev Neurol (Paris) 1985;141:349-70.

35 Scudder CA. Personal communication, 1989.
36 Highstein SM, Cohen B, Matsunami K. Monosynaptic projections from the pontine reticular formation to the IIIrd nucleus in the cat. Brain Res 1975;75:340-4.

37 Grantyn A, Grantyn R, Gaunitz U, Robiné KP. Sources of direct excitatory and inhibitory inputs from the medial rhombencephalic tegmentum to lateral and medial rectus motoneurons in the cat. Exp Brain Res 1980;39:49-61.

38 Matano S. Experimental Studies on the medial longitudinal fasciculus in the rabbit. V. Ascending fibers from the reticular formation and the oculomotor system. reticular formation and the
J Hirnforsch 1970/71;12:241-53.

39 Goebel HH, Komatsuzaki A, Bender MB, Cohen B. Lesions of the pontine tegmentum and conjugate gaze paralysis. Arch Neurol 1971;24:431-40.

40 Büttner-Ennever JA, Miles TA, Henn V. The role of the pontine reticular formation in oculomotor function. Exp Brain Res 1975;23 (Suppl):31.

41 Remmel RS, Skinner RD, Pola J. Cat pontomedullary reticular neurons projecting to the regions of the ascending MLF and the vestibular nuclei. In: Baker A, Berthoz A, eds. Control of gaze by brainstem neurons, Amsterdam: Elsevier 1977:163-6.

42 Hassler O. Arterial pattern of human brainstem. Normal appearance and deformation in expanding supratentorial conditions. Neurology 1967;17:368-75.

43 Duvernoy AM. Human brainstem vessels. Berlin: Springer, 1978.

44 Nieuwenhuys $R$, Voogd J, van Huijzen C: The human central nervous system. 3rd ed. Berlin: Springer, 1989.

45 Fötzsch R. Die internukleären Ophthalmoplegien. Bemerkungen zu der Arbeit von R. Schiffter. Nervenarzt 1976;47:258-60.

46 Cogan DG. Internuclear ophthalmoplegia, typical and atypical. Arch Ophthalmol 1970;84:583-9.

47 Gomez CR, Gomez SM, Selhorst JB. Acute thalamic esotropia. Neurology 1988;38:1759-62.

48 Kommerell G, Olivier D, Theopold H. Adaptive programming of phasic and tonic components in saccadic eye movements. Invest Ophthalmol 1976;15:657-60.

49 Caplan LR. "Top of the basilar" syndrome. Neurology 1980;30:72-9.

\section{Neurological stamp}

\section{William Harvey 1578-1657}

An outstanding scientific event of the 17th century was Harvey's description of the circulation of the blood. It was Guilio Casserio, Professor at Padua and one of Harvey's teachers, who first illustrated the Circle of Willis.

Harvey took a great interest in the function of the nervous system and combined the concepts of his predecessors. In his opinion voluntary movements were under the control of the brain, whereas involuntary movements were not. Among his observations he noted a decapitated cock continued to move in a convulsive irregular fashion. He distinguished motor from sensory nerves and observed that peripheral sensation passed to the brain. Harvey also described epilepsy and a suspected case of syringomyelia.

He was the first British writer to make a substantial contribution to midwifery. In his book on Generation a chapter entitled De Partu is devoted to obstetrics. He considered the fetus assisted its own delivery by active movement comparable to a chicken emerging from an egg or a butterfly from a chrysalis. False pregnancies are also mentioned. In one case he describes how he was unable to dissuade a woman from her fixed idea that she was pregnant, “. . . and all the arguments I could suggest could not remove that persuasion from her: till at the last, all her hopes vanished into flatulency and fatness".

In 1978 Russia issued a postage stamp commemorating the 400th anniversary of the birth of William Harvey. (Stanley Gibbons No 4790, Scott No 5677.)

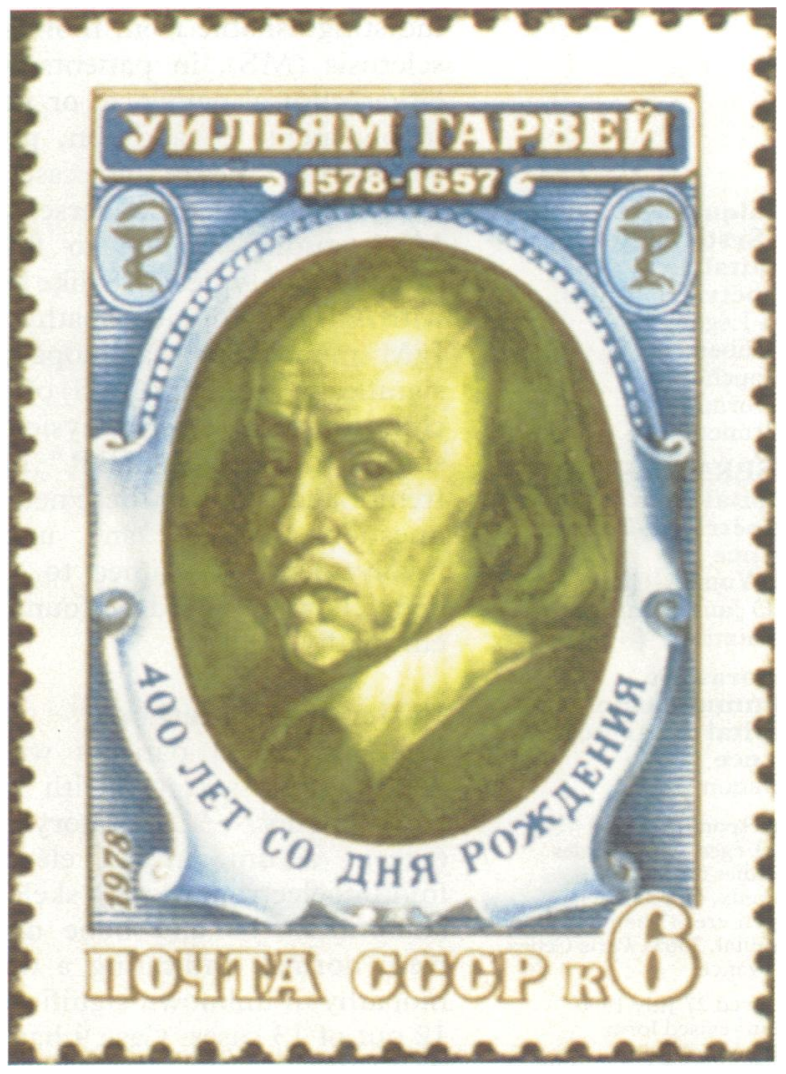

